\title{
Origins and molecular pathology of ovarian cancer
}

\author{
Debra A Bell \\ Department of Pathology, Massachusetts General Hospital and Harvard Medical School, Boston, \\ $M A, U S A$
}

\begin{abstract}
Epithelial ovarian cancer comprises the majority of malignant ovarian tumors in adult women. These neoplasms are classified into distinct morphologic categories based on the appearance of the epithelium into tumors of serous, mucinous, endometrioid, clear cell, transitional, squamous, mixed and undifferentiated type. Current data indicate that each of these histologic subtypes is associated with distinct morphologic and molecular genetic alterations: high-grade serous and possibly endometrioid carcinomas most probably arise from surface epithelial inclusion glands with TP53 mutations and dysfunction of BRCA1 and/or BRCA2; low-grade serous carcinomas probably arise in a stepwise fashion in an adenoma-borderline tumor-carcinoma sequence from typical to micropapillary borderline tumors to low-grade invasive serous carcinoma via activation of the RAS-RAF signaling pathway secondary to mutations in KRAS and BRAF; mucinous carcinomas arise via an adenoma-borderline tumor-carcinoma sequence with mutations in $K R A S$; low-grade endometrioid carcinomas arise from endometriosis via mutations in CTNNB1 (the gene encoding $\beta$-catenin) and PTEN. Although the morphologic data strongly support an origin of clear cell carcinoma from endometriosis, there is limited data on the genetic alterations in these uncommon tumors. Thus it is likely that most low-grade, relatively indolent ovarian carcinomas of serous, mucinous and endometrioid type arise from pre-existing cystadenomas or endometriosis whereas most high-grade serous carcinomas arise without an easily identifiable precursor lesion.
\end{abstract}

Modern Pathology (2005) 18, S19-S32. doi:10.1038/modpathol.3800306

Keywords: ovarian cancer; ovarian borderline tumors; histogenesis; molecular pathology

Epithelial ovarian cancer comprises the majority of malignant ovarian tumors in adult women. These neoplasms are classified into distinct morphologic categories based on the appearance of the epithelium into tumors of serous, mucinous, endometrioid, clear cell, transitional, squamous, mixed and undifferentiated type. ${ }^{1,2}$ Two types of ovarian surface epithelial lesions have been described as possible precursors of these carcinomas: lesions that appear in situ in surface epithelium or surface epithelial inclusion glands (SEIG); and preexisting benign epithelial ovarian tumors and endometriosis. The morphologic and genetic data implicating each as a precursor lesion of the major histologic subtypes of ovarian carcinoma are discussed.

Correspondence: Dr DA Bell, MD, Department of Pathology, Warren 105, Massachusetts General Hospital, Fruit Street, Boston, MA 02114, USA.

E-mail: dbell@partners.org

Received and accepted 27 August 2004

\section{Surface epithelium and surface epithelial inclusion glands as precursor lesions}

\section{Morphologic Data}

Two types of morphologic data are available regarding the malignant potential of ovarian surface epithelium and inclusion glands, alterations in these structures and studies on microscopic ovarian carcinoma.

\section{Surface epithelium and surface epithelial inclusion} glands

Despite the widespread acceptance of the origin of surface epithelial cancers from the ovarian surface epithelium and its inclusion glands, only rarely have putative precursor lesions been described at these sites. Two types of lesions have been suggested as possible precursors: proliferativemetaplastic changes and cytologic atypia. Ovaries have been examined for such lesions in four settings: (1) prophylactic oophorectomy specimens from patients with a strong family history of ovarian cancer or breast cancer or both, or with known $B R C A 1$ or BRCA2 gene mutations; (2) uninvolved 
ovaries contralateral to ovarian carcinomas or benign or borderline epithelial tumors or a combination of these tumors; (3) surface epithelium and epithelial inclusion glands adjacent to invasive ovarian carcinomas; (4) ovaries removed after positive or suspicious cul-de-sac aspirates performed to screen for ovarian cancer.

Unfortunately, most studies of the surface epithelium are limited by its fragility; it is usually denuded by allowing the surface to dry intraoperatively or by touching or rubbing it during removal or gross pathologic examination. ${ }^{3,4}$ As a result, often all that remains for microscopic examination is residual intact epithelium either in crevasses below a gyriform surface or under the protection of fibrous adhesions.

Only rare examples of lesions showing significant epithelial atypia (severe dysplasia or carcinoma in situ) of the ovary have been reported. ${ }^{5-11}$ These lesions are characterized by stratification of cells lining the ovarian surface or epithelial inclusion glands with loss of nuclear polarity and marked nuclear pleomorphism, hyperchromasia and chromatin clumping (Figure 1). In their study of cul-desac aspirates obtained for ovarian cancer screening, Graham et $a l^{9}$ identified these changes adjacent to a microscopic serous carcinoma in one patient and in the surface epithelium of 20 additional patients with malignant cells in their aspirates. ${ }^{7,8}$ Bell and Scully ${ }^{6}$ noted severe cytologic atypia adjacent to or near incidentally detected microscopic invasive ovarian carcinomas in three of 14 women, and Gusberg and Deligdisch $^{5}$ noted such changes in two of three women whose ovaries had been removed prophylactically because of the finding of ovarian carcinoma in an identical twin. Mild-to-moderate atypia was noted in the third twin, and has also been reported in surface epithelium adjacent to grossly visible or microscopic ovarian carcinomas. ${ }^{6,12-14}$ Ovarian carcinoma-in situ has been reported in only
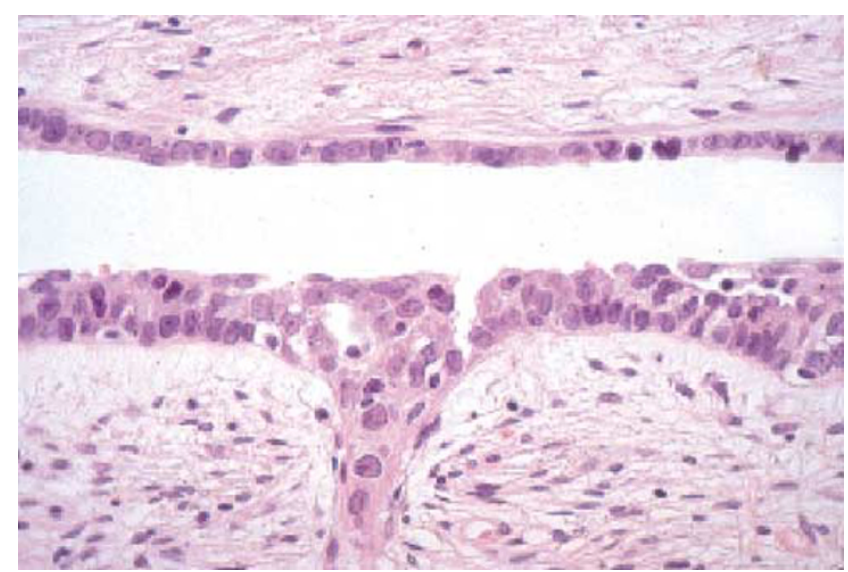

Figure 1 Ovarian carcinoma in situ. The epithelium is thickened by stratified cells showing loss of nuclear polarity and marked nuclear pleomorphism, hyperchromasia and chromatin clumping. a single prophylactic oophorectomy specimen. This patient underwent a hysterectomy and bilateral salpingo-ooporectomy for persistent bleeding on Tamoxifen. ${ }^{11}$ Sherman et $a l^{4}$ identified mild atypia of the surface epithelium more frequently in the ovaries of women at increased risk for ovarian carcinoma (prophylactically removed ovaries from women with a strong family history of ovarian cancer or known BRCA mutations, or ovaries contralateral to ovarian cancer) than controls. Although this difference was statistically significant, the number of cases was small. Werness et al ${ }^{15}$ were unable to identify a difference in the frequency of atypia in prophylactically removed ovaries and controls on light microscopic examination, but demonstrated a statistically significant increase in nuclear enlargement and chromatin heterogeneity in prophylactically removed ovaries morphometrically. Several other groups have failed to demonstrate epithelial atypia in the prophylactic oophorectomy specimens from women with a strong family history of ovarian cancer ${ }^{16}$ or with known BRCA1 or 2 mutations. ${ }^{17,18}$ Two groups of investigators have noted mild atypia of the surface epithelium in uninvolved ovaries contralateral to ovarian carcinomas or borderline tumors; ${ }^{4,19}$ the latter group, however, failed to detect atypia in epithelial inclusion glands. Several other investigators were unable to demonstrate a statistically significant increase in atypia in ovaries contralateral to ovarian tumors over control ovaries. ${ }^{20,21}$ Deligdisch et $a 1^{22}$ have noted 'ovarian dysplasia' as detected by a morphometric method utilizing discriminant analysis based on nuclear area and texture in both prophylactic oophorectomy specimens and in epithelium adjacent to carcinomas.

Although early studies had suggested that proliferative or metaplastic changes of the ovarian surface epithelium such as papillae, epithelial stratification and tufting, and metaplasia are precursors of ovarian carcinoma, ${ }^{23}$ similar findings have been reported to be increased in frequency in only one more recent large series of prophylactic oophorectomy specimens from women with a strong family history of ovarian cancer. ${ }^{16}$ The remainder of the recent studies $^{4,15,17,18,24}$ have failed to demonstrate any differences in the frequency of these histologic features between cases and controls. A few such studies have shown an increase in the number of inclusion cysts in prophylactic oophorectomy specimens $^{15}$ and in ovaries contralateral to ovarian carcinoma ${ }^{25}$ others have failed to confirm these findings. ${ }^{16,19-21}$

\section{Microscopic surface-epithelial carcinomas}

A very small number of microscopic or tiny gross carcinomas have been reported, usually as incidental findings at operations for other gynecologic disorders or, more recently, in prophylactic oophorectomy specimens from patients at high risk for the development of ovarian carcinoma. ${ }^{6,8,9,16,22,26-28}$ The 
largest study of such cases and the only one to include meaningful follow-up data was reported prior to widespread $B R C A$ mutation testing and comprised 14 cases of ovarian carcinomas that had not been recognized preoperatively, intraoperatively or even on gross examination of the ovaries but were discovered only on microscopic examination. ${ }^{6}$ The patients ranged in age from 27 to 65 (mean 50) years. Three women had a family history of ovarian cancer, six did not, and the family history was unknown or unreliable in the remaining cases. All of the tumors were incidental findings in patients operated on because of a gynecologic indication that did not include a suspicion of ovarian cancer. The tumors ranged in diameter from less than 1 to $7 \mathrm{~mm}$. All of them were unilateral and four appeared to be multifocal. Surface involvement was found in five of the 13 cases in which this feature could be evaluated. The tumors had the typical microscopic features of larger clinically apparent tumors of the same cell type and were classified as serous in 10 cases, endometrioid in one, clear cell in one and undifferentiated in two. In all, 12 of the 14 tumors were grade 2 or 3 (Figure 2). Follow-up data of 2 or more years duration were available for 10 of the 14 patients. Five of the seven whose diagnoses had been made prospectively at the time of oophorectomy were alive without recurrence 2-12 years postoperatively. At the time of publication of the series one patient was alive with recurrent tumor and one had died of tumor. Subsequently, at least one patient originally categorized as alive without recurrence had died of tumor. Two of the three women whose ovarian tumors had been diagnosed for the first time on retrospective microscopic examination of previously removed ovaries after the development of peritoneal carcinomatosis 6,7 and 10 years subsequently died and the third was alive with recurrent tumor.

Recent studies on prophylactic oophorectomy specimens from women with BRCA 1 or 2 mutations have revealed surprisingly few cases of early ovarian

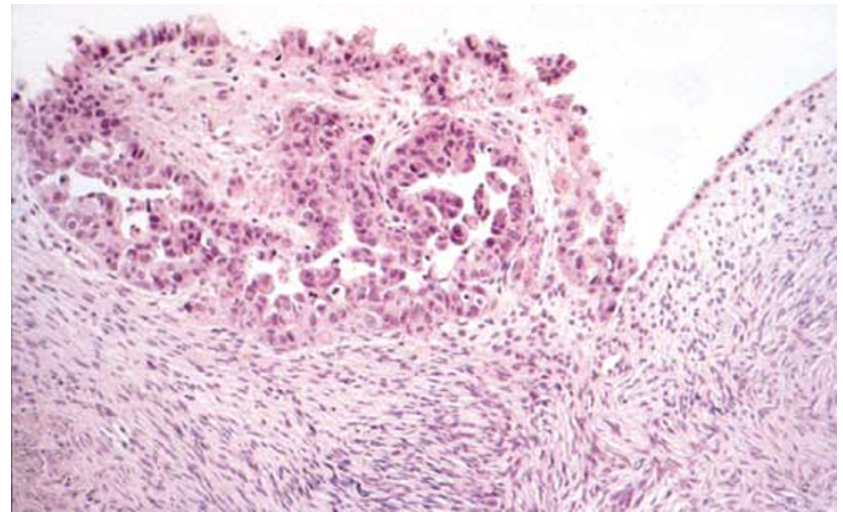

Figure 2 High-grade serous microcarcinoma. The tumor is present on the ovarian surface and in the superficial cortex. carcinoma (three at the date of this review). ${ }^{22,28-30}$ One of these patients died of tumor. ${ }^{29}$

Clearly, although the data are limited, the prognosis of patients with minute ovarian epithelial cancers is guarded. It is unclear, however, whether the subsequent peritoneal tumor in these women reflect late metastasis from the ovarian carcinoma or the development of a second primary tumor of the peritoneum. Further studies are necessary to answer this question.

\section{Fallopian tube as the primary site of origin of epithelial ovarian carcinoma}

Although very few cases of ovarian carcinoma-in situ or severe cytologic atypia or minute carcinomas have been identified in prophylactic salpingooophorectomy specimens, each such study that has included careful sampling of the fallopian tubes has reported examples of tubal carcinoma-in situ or severe atypia or small tubal carcinomas, especially in women with BRCA1 mutations. ${ }^{30-34}$ These findings have engendered speculation that 'ovarian' carcinomas in women with BRCA1 mutations may originate from undetected exfoliated tubal carcinomas $^{30,33,35}$ and have led to the suggestion that ovarian and fallopian tube carcinomas in women with BRCA mutations should be termed 'female adnexal carcinoma'. ${ }^{24,35}$

\section{Molecular Genetic Data}

\section{Surface epithelial inclusion glands}

Only a small number of studies have examined the molecular genetic features of surface epithelium, its inclusion cysts or early carcinomas. Several small studies have examined the immunohistochemical expression of proliferation and differentiation-related proteins in nonatypical ovarian surface epithelium and SEIG in prophylactic oophorectomy specimens compared to controls. ${ }^{15,18,24,36,37}$ Most of these studies failed to document differences in expression of p53, c-erbB2, and Ki67 in surface epithelium or SEIG. Additionally, Piek et $a l^{24}$ also failed to note differences in expression of p21, p27, cyclin A, cyclin D, and estrogen receptor in surface epithelium or SEIG in prophylactic oophorectomy specimens vs controls. They did note increased expression of bcl-2 and progesterone receptor in SEIG epithelium in prophylactic oophorectomy specimens, however. In contrast, one study $(36,37)$ found p53 overexpression in cortical clefts or inclusion cysts in 10 of 37 patients with $B R C A$ mutations, and TP53 mutations in three of these, two of which showed loss of heterozygosity (LOH) of wild-type BRCA 1 or 2 alleles. Nnene et a ${ }^{38}$ have noted that an increased level of morphologic abnormalities of ovarian surface epithelium and SEIG is associated with expression of p53 in normal ovaries, suggesting that abnormalities of p53 are an early event. 
High-grade serous carcinomas

It has been well established that TP53 mutations are frequent in both hereditary and sporadic high-grade serous carcinoma. ${ }^{38-47}$ It has also been demonstrated that loss of BRCA1 or BRCA2 function by a variety of mechanisms is present in the majority of both sporadic and hereditary high-grade serous and endometrioid carcinomas. ${ }^{48,49}$ Boyd and coworkers $^{36,37}$ and Mok and Bell (unpublished data) demonstrated TP53 mutations in microcarcinomas and Werness et al ${ }^{11}$ demonstrated loss of heterozygosity at BRCA1 and TP53 and overexpression of p53 in one microscopic ovarian surface carcinomain situ. A few studies have examined genetic abnormalities in surface epithelium or SEIG adjacent to coexisting conventional serous carcinoma. Hutson et $a 1^{10}$ demonstrated overexpression of p53 in SEIG associated with coexisting carcinoma. and Boyd and coworkers ${ }^{36,37}$ demonstrated the same mutation in the carcinoma and the adjacent normal or atypical epithelium in a small number of cases. These data suggest that mutation of TP53 is an early event in the development of ovarian carcinoma and is present prior to stromal invasion. Additionally, Shridhar et $a l^{50}$ found that early (Stage I) compared to advanced (Stage III) carcinomas (that were mostly high-grade serous carcinomas) have similar patterns of gene expression.

\section{Conclusions}

These data demonstrating increasing atypia and common and accumulating genetic alterations in surface epithelial inclusion glands, ovarian 'carcinoma in situ', microcarcinomas and typical highgrade serous carcinoma suggest that high-grade serous and perhaps endometrioid ovarian adenocarcinomas arise from these structures. Additionally, the data from a small number of cases indicates that TP53 mutation occurs in preinvasive epithelium with loss of BRCA1 or BRCA2 function in the majority of tumors, findings compatible with the high degree of genetic instability of these tumors. The suggestion that ovarian carcinomas are surface implants of occult fallopian tube carcinomas is deserving of further study.

\section{Benign and borderline serous tumors as precursor lesions}

Whether surface epithelial cancers arise in preexisting benign or borderline epithelial tumors of the same cell type and, if so, how often, has been specifically studied only recently. Benign ovarian neoplasms are almost always removed as soon as they are detected, and therefore their natural history is largely unknown. Evidence of a benign to malignant transformation is largely circumstantial and includes: (1) a generally observed older-age incidence of carcinomas than benign tumors of the same cell type; in that most investigators have reported progressively higher mean ages for benign, borderline, and invasive tumors in both the serous and mucinous categories, with average ages for the combined categories 44,48 and 56 years, respectively; ${ }^{51}$ (2) a reported five-fold increase in the frequency of benign epithelial tumors in first- and second-degree relatives of women with ovarian carcinoma; ${ }^{52}$ (3) the presence of enlarging ovarian cysts on ultrasound prior to the development of carcinoma, ${ }^{53}$ and (4) the frequent observation of various combinations of benign, borderline, and invasive neoplasia within the same specimen; ${ }^{54,55}$

\section{Morphologic Data}

\section{Benign serous tumors}

Several studies have shown a relatively low frequency of coexisting benign serous epithelium and serous carcinomas (the great majority of which were high grade) of $15-56 \%$, and it is unusual to encounter a high-grade serous carcinoma as an incidental finding in a serous cystadenoma or borderline tumor, although such cases are rarely encountered. ${ }^{54-56}$

\section{Serous borderline tumors}

It is rare to see high-grade serous carcinoma arising in a serous borderline ovarian tumor of either typical or micropapillary type. It has been shown recently, however, that the majority of low-grade invasive serous ovarian carcinomas arise in association with serous borderline ovarian tumors of micropapillary type ${ }^{57}$ which in turn usually coexist with serous borderline tumors of the typical type (Figure 3a-d). ${ }^{57-61}$

\section{Molecular Genetic Data}

\section{Benign serous tumors}

Most studies have not detected p53 overexpression or TP53 mutations (which are common in high-grade serous carcinomas) in serous cystadenomas. ${ }^{62-65}$ However, a recent study utilizing microdissection ${ }^{66}$ found TP53 mutations in 6\% $(2 / 24)$ of benign serous tumors. Zheng et $a l^{67}$ and Wolf et $a l^{68}$ found that benign cysts in continuity with serous carcinomas have similar cytogenetic and mutational changes, suggesting that such cysts already have genetic abnormalities that predispose them to malignant transformation. An alternative interpretation is that such benign-appearing epithelium represents morphologic maturation of malignant epithelium and does not indicate a benign precursor lesion. Thomas et $a l^{66}$ noted a surprisingly high frequency of LOH of $73 \%$ on at least one chromosome arm in benign serous tumors when 56 microsatellite markers on chromosomes 6, 7, 9, 11 and 17 (chromosomes that exhibit frequent $\mathrm{LOH}$ in typical ovarian carcinomas) were analyzed. The specific frequencies of $\mathrm{LOH}$ 

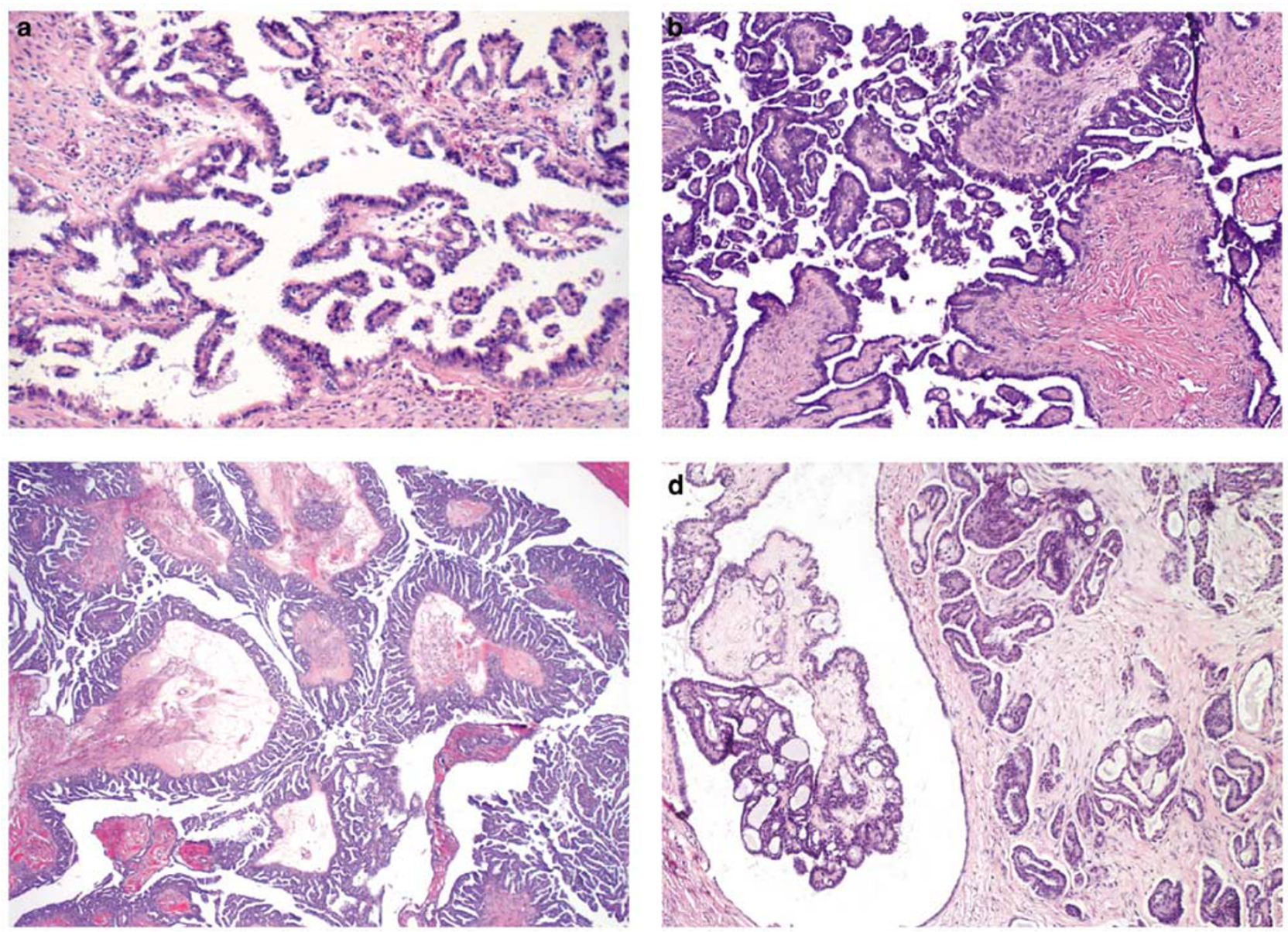

Figure 3 Probable progression of serous borderline tumor to invasive low-grade serous carcinoma. (a) Typical serous borderline tumor. (b) Typical serous borderline tumor (lower portion of field) coexisting with micropapillary serous borderline tumor. (c) Micropapillary serous borderline tumor. (d) Micropapillary serous borderline tumor with stromal invasion by low-grade serous carcinoma (right).

were $8,23,7,10$ and $7 \%$ for chromosomes $6,7,9,11$ and 17 , respectively. In contrast, Tapper et $a l^{69}$ found significant differences in gene expression between benign and malignant serous ovarian tumors.

\section{Serous borderline tumors compared to high- and} low-grade serous carcinoma

Most studies of serous neoplasms have shown different molecular changes in serous cystadenomas, borderline tumors and high-grade carcinomas, indicating that in most cases these tumor types develop via different genetic pathways. ${ }^{42,70-74}$ TP53 mutations and p53 immunohistochemical overexpression are uncommon in borderline serous tumors, whereas approximately $60 \%$ of high-grade serous carcinomas have detectable mutations or overexpression of TP53. ${ }^{38-42,44,45}$ Serous borderline tumors have a higher rate of KRAS mutations $(27-36 \%)$ than high-grade serous carcinomas (0-12\%). ${ }^{40,46,47,75-78}$ BRAF mutations, which are seen in $33-50 \%$ of serous borderline tumors of typical or micropapillary type, have not been identified in high-grade serous carcinoma. ${ }^{74,76,78}$

A few studies analyzing and comparing serous borderline tumors and low-grade serous carcinomas have been performed only recently. These studies have found a similar frequency of KRAS mutations in approximately one-third of typical or micropapillary serous borderline tumors and invasive lowgrade serous carcinomas (invasive micropapillary serous carcinoma), and BRAF mutations in an additional similar proportion. Interestingly, KRAS and $B R A F$ mutations are present only very rarely in the same neoplasm; thus, in aggregate these mutations are present in $60 \%$ of serous borderline ovarian tumors and $68 \%$ of low-grade serous carcinomas. ${ }^{74,76,78}$ In contrast, BRAF mutations have not as yet been reported in high-grade conventional serous carcinoma and KRAS mutations have been reported only rarely $(0-12 \%))^{46,74,76,78}$

Studies utilizing other techniques have also demonstrated substantial differences between borderline tumors and/or low-grade serous carcinomas and high-grade serous carcinomas. One study has 
demonstrated that the allelic imbalance index gradually increases from typical to micropapillary serous borderline tumor to invasive low-grade serous carcinoma in contrast to the finding of high levels of allelic imbalance in even tiny high-grade ovarian serous carcinomas, ${ }^{73}$ (Mok, Bell unpublished data). Comparative genomic hybridization (CGH) studies have also demonstrated differences between low- and high-grade serous carcinomas in that high-grade serous carcinomas showed significantly higher CNA frequencies than low-grade tumors. ${ }^{79-81}$ Differences between low- and highgrade tumors were also demonstrated genetically. High-grade carcinomas showed under-representation of $11 p$ and $13 q$, and over-representation of $8 q$ and $7 p$, while $12 p$ under-representation and $18 p$ over-representation were present significantly more frequently in well and moderately differentiated tumors. ${ }^{82}$

These findings suggest that invasive low-grade serous carcinomas (or invasive micropapillary serous carcinomas) and high-grade serous carcinomas arise via different pathways, with low-grade carcinomas most probably arising in an adenomacarcinoma sequence, with a progression from typical to micropapillary borderline tumors to invasive lowgrade carcinoma via alteration of the RAS-RAF signaling pathway by mutations in either KRAS or $B R A F^{73-79}$

\section{Conclusions}

These data indicate that low- and high-grade serous carcinomas, in the great majority of cases, arise via different genetic pathways. Low-grade serous carcinomas most probably arise via an 'adenoma-borderline tumor-carcinoma' progression from typical to micropapillary serous borderline tumor to low-grade serous carcinoma via alteration of the RAS-RAF signaling pathway secondary to mutations in KRAS and BRAF. As noted in the previous section, high-grade serous carcinomas most probably arise from SEIG in the great majority of cases with TP53 mutations and BRCA1 or BRCA2 dysfunction.

\section{Benign and borderline mucinous tumors as precursor lesions}

\section{Morphologic Data}

The studies of Scully et $a l^{54}$ and Puls et $a l^{55}$ showed coexisting benign mucinous epithelium in primary ovarian mucinous carcinomas in $74-90 \%$ of cases. Several recent detailed studies of invasive primary mucinous ovarian carcinomas of gastrointestional type showed coexisting mucinous borderline tumor in $67-69 \%$ of cases (Figure $4 a, b) .^{83,84}$ The two studies describing endocervical-like mucinous carcinomas reported coexisting Mullerian mucinous or
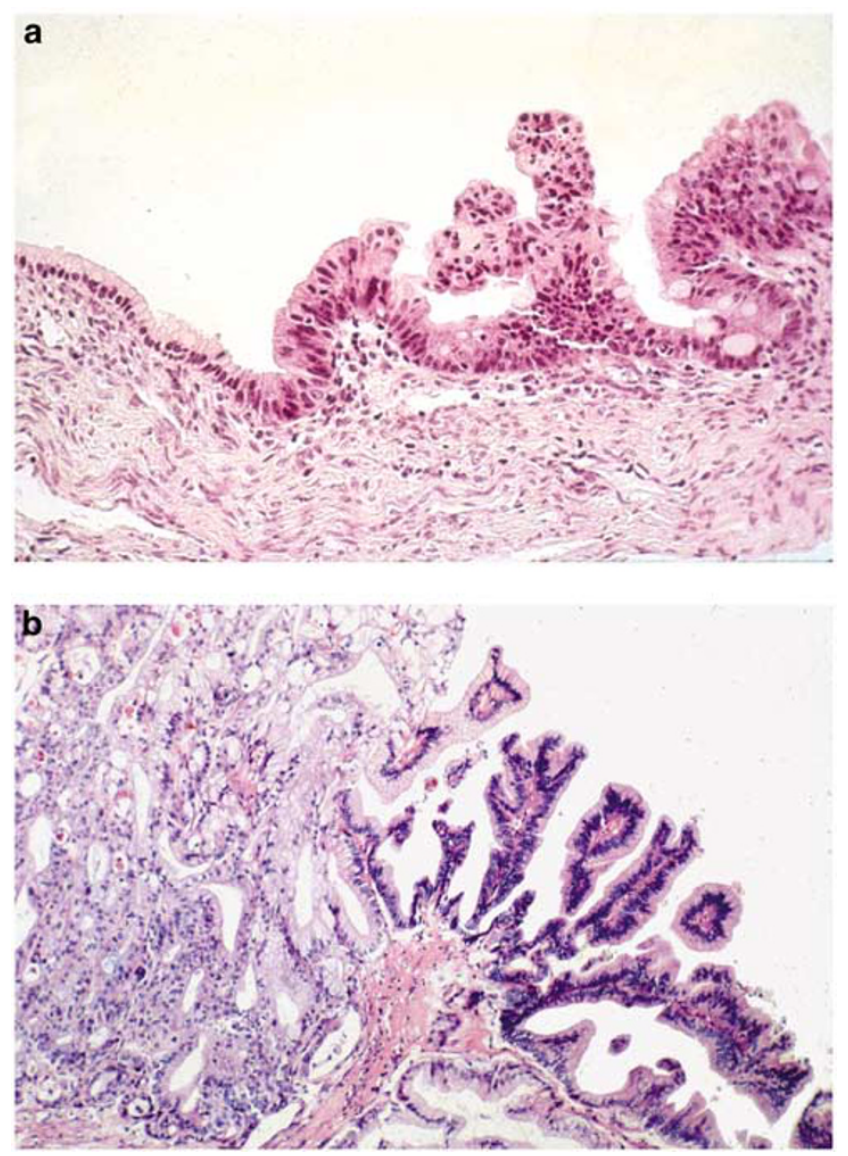

Figure 4 Probable progression of mucinous cystadenoma to mucinous carcinoma. (a) Mucinous cystadenoma (left) with a transition to mucinous borderline tumor (right). (b) Mucinous borderline tumor (right) in continuity with mucinous carcinoma (left).

mixed cell type borderline tumors in $75-100 \%$ of cases. $^{85,86}$ These morphologic findings are highly suggestive that mucinous carcinomas arise from preexisting benign and borderline mucinous tumors.

\section{Molecular Genetic Data}

Greater similarities in mutation rates and overexpression of oncogenes and tumor suppressor genes have been reported in benign, borderline and malignant mucinous tumors than serous tumors. Most studies have shown a high and increasing frequency of KRAS mutations in mucinous cystadenomas, borderline tumors and carcinomas, ranging from 33 to $86 \% .^{47,70,72,75,87,88}$ Several groups ${ }^{75,87,88}$ have noted similar KRAS mutation patterns in benign, borderline and malignant mucinous areas within the same neoplasm, which suggests that KRAS mutation is an early event in mucinous tumorigenesis. It has also been noted that the rate of TP53 mutations is lower in mucinous borderline tumors than mucinous carcinomas (13 vs $40 \%)^{38,70,77}$ In contrast to serous borderline tumors, 
mucinous borderline tumors have not shown $B R A F$ mutations. $^{78,89}$ These data suggest that ovarian mucinous carcinomas arise via an adenoma-borderline tumor-carcinoma sequence with activation of the RAS-RAF signaling pathway by KRAS mutations. ${ }^{78,89}$

\section{Conclusions}

The majority of mucinous ovarian carcinomas arise via an adenoma-borderline tumor-carcinoma sequence with activation of the RAS-RAF signaling pathway secondary to KRAS mutations.

\section{Endometriosis as a precursor lesion}

Endometriosis, particularly cystic ovarian endometriosis, has been shown to be related to an increased risk of developing ovarian endometrioid and clear cell carcinoma in several epidemiologic studies. ${ }^{90-94}$ Endometriosis-associated ovarian carcinomas are more frequently low-grade and low stage and have a more favorable prognosis than carcinomas not associated with endometriosis. ${ }^{90}$ It has also been noted in one clinical study that $20 \%$ of endometrioid and $88 \%$ of clear cell carcinomas were preceeded by an ultrasonographically detected endometriotic cyst. ${ }^{53}$

\section{Morphologic Data}

Many types of neoplasms have been documented to arise in endometriosis morphologically, particularly endometrioid and clear cell carcinomas, and rarely, other types of surface epithelial carcinomas and even mesenchymal tumors such as endometrioid stromal sarcoma. ${ }^{1,95-98}$ Endometrioid carcinoma has been reported to originate directly from endometriotic tissue in up to $24 \%$ of the cases in various series (Figure 5). Ipsilateral ovarian endometriosis has been detected in $11-31 \%$, ovarian endometriosis

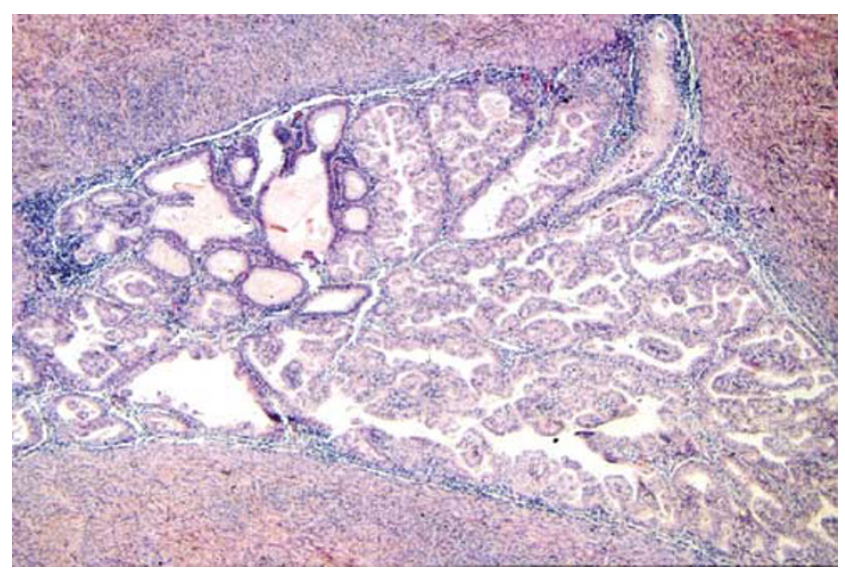

Figure 5 Endometrioid adenocarcinoma arising in endometriosis. of unspecified laterality in 9-20\%, and pelvic endometriosis in $11-28 \%$ of cases of ovarian endometrioid carcinoma. ${ }^{96,99-107}$ Well-differentiated or low-grade endometrioid ovarian carcinomas are associated with an especially high frequency of associated endometriosis $(63 \%)$ or endometrioid adenofibromas $(47 \%))^{108}$

Russell ${ }^{104}$ reported a $47 \%$ frequency of pelvic endometriosis in 30 cases of clear cell carcinoma of the ovary, and Aure et al ${ }^{99}$ demonstrated a $24 \%$ frequency of ovarian endometriosis in 59 cases of the same type of tumor; both of those figures were surprisingly higher than the figures given by the same authors for the association of endometriosis with endometrioid carcinoma (28 and 9\%, respectively). Although isolated examples of serous and mucinous carcinoma have been reported to originate in endometriosis, the association of these tumors in general with that disorder is not significant. Russell ${ }^{104}$ found only a $2.5 \%$ frequency of pelvic endometriosis in 163 cases of serous carcinoma and a $6 \%$ frequency in 17 cases of mucinous carcinoma; and Aure et a $1^{99}$ detected no ovarian endometriosis in 283 cases of serous carcinoma and only an $0.8 \%$ frequency, in 203 cases of mucinous carcinoma. Rutgers and Scully, ${ }^{109}$ however, reported the finding of ovarian endometriosis in $30 \%$ of cases of mucinous borderline tumors of endocervical-like (Müllerian) type, which accounted for $15 \%$ of the mucinous borderline tumors in their series; in contrast, there was no significant association of ovarian endometriosis and the more common mucinous borderline tumor of intestinal type. Borderline tumors of mixed Müllerian epithelial cell types also have a frequent association with ovarian endometriosis. ${ }^{110}$

Hyperplasia in endometrosis as a precursor lesion Because carcinoma of the endometrium often arises on a background of hyperplasia with cytologic and architectural atypicality, one might expect that a proportion of carcinomas arising in endometriosis would have similar precursors. Hyperplasia with varying degrees of architectural and cytologic atypia resembling that seen in the endometrium occurs in $2-7 \%$ of cases of ovarian endometriosis or ovarian endometriotic cysts without coexisting carcinoma and in $67-100 \%$ of endometriosis associated with coexisting carcinoma (Figure 6). ${ }^{1,95,111-116}$ The prognostic significance of such changes is unclear because follow-up data have been limited to only a small number of women. Seidman ${ }^{113}$ reported follow-up information on 13 women with complex atypical hyperplasia and seven women with 'early carcinoma', arising in ovarian endometriosis. All the women with complex atypical hyperplasia were followed for a mean of 8.5 years and survived without the development of carcinoma, however, most of the lesions were completely excised. Similarly, the four women with 'adenomatous hyperplasia' in ovarian endometriosis in the report 
S26

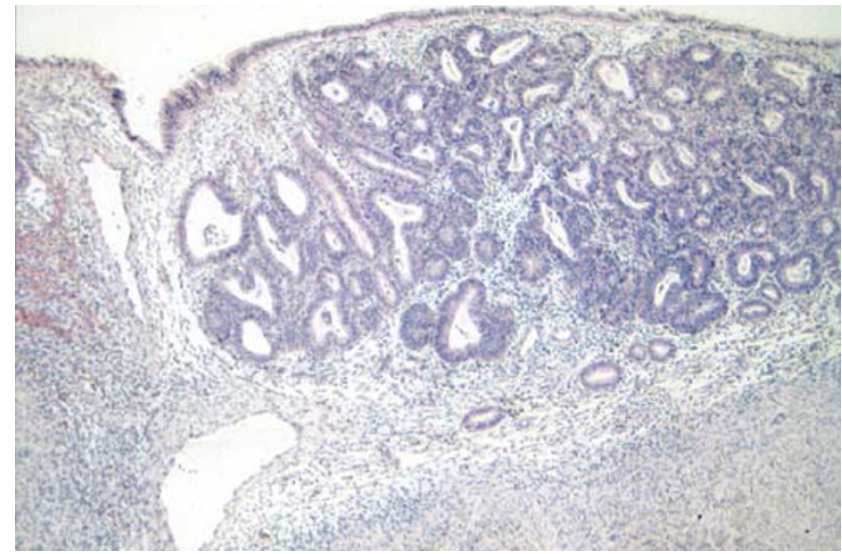

Figure 6 Atypical endometrial-like hyperplasia arising in an ovarian endometriotic cyst.

of Czernobilsky and Morris ${ }^{111}$ were followed for $3-5$ years without recurrence or the development of carcinoma, although 10 of their 11 patients with 'adenomatous hyperplasia' or severe atypia of cyst lining epithelium were treated by oophorectomy, presumably excising completely the atypical lesion. We have observed one case, however, in which the left ovary of a 55-year-old woman, which contained severely atypical endometriotic tissue, was dissected away from the pelvic wall; she received estrogen therapy for 3 years, and subsequently returned with an endometrioid adenocarcinoma that had arisen in the area where ovarian tissue had presumably been left behind. The outcome in this case is interesting in light of epidemiologic studies that have demonstrated a significant increase in the incidence of endometrioid carcinoma of the ovary in women on estrogen therapy ${ }^{117,118}$ and in view of the number of reported cases of carcinoma developing in endometriosis in women receiving replacement therapy with estrogens unopposed by progesterone. ${ }^{98}$

\section{Early carcinoma in endometriosis}

Early carcinoma developing in an endometriotic cyst has also been specifically described in detail in only a few studies. Seidman ${ }^{113}$ reported 11 examples of ovarian endometriosis containing foci that fulfilled the Kurman and Norris ${ }^{119}$ criteria for endometrioid carcinoma of the endometrium. Seven women were followed for a mean of 8.6 years; in 'most' of the cases the lesions had been completely excised. Nevertheless, three of them had an adverse outcome. One had a poorly differentiated adenocarcinoma of the anterior vaginal wall 8.1 years later, one had an endocervical-like mucinous borderline tumor in the contralateral ovary 7 years later and the third patient was found to have 'early carcinoma' in foci of endometriosis in the contralateral ovary and the omentum 3 months after the initial diagnosis. Thus, although the prognosis of an individual completely excised example of early carcinoma arising in endometriosis is excellent, carcinoma may arise in residual foci of endometriosis at the same or other sites. For this reason, close follow-up of women with early carcinoma arising in endometriosis is warranted.

\section{Atypical cyst lining cells as a precursor lesion} Two additional atypical lesions encountered in endometriosis-but rarely, if ever, in the endometrium-are characterized by cells showing varying degrees of atypia lining endometriotic cysts without endometrial glandular hyperplasia. In the first type, which comprises most of these cases, the lining epithelium is composed of a single layer of large polygonal cells with abundant eosinophilic cytoplasm and large hyperchromatic, often smudged nuclei. Acute inflammation is frequently present (Figure 7). ${ }^{113,115,120,121}$ In the second less common type, large polygonal cells and hobnail cells are present with epithelial stratification and tufting. These cells may have eosinophilic, clear, or vacuolated cytoplasm and may contain intracytoplasmic mucin; their nuclei are usually markedly hyperchromatic and pleomorphic. This type of epithelium may also be associated with acute inflammation $^{111,113,114,120,122,123}$ and with mucinous endocervical-like (Mullerian) borderline tumors. ${ }^{109,121}$ Seidman ${ }^{113}$ obtained follow-up on 20 of 37 women with these two types of cyst lining atypias and found that the patients were all alive without the development of carcinoma after a mean of 8.6 years; 'most' of the lesions, however, were completely excised. Czernobilsky and Morris ${ }^{111}$ reported that seven women with the second type of lining atypia were followed for 3-5 years without the development of carcinoma; again, most of the lesions were completely excised. Based on this data, Seidman ${ }^{113}$ concluded that endometriotic cyst lining atypia was probably reactive or degenerative. In contrast, Moll et $a 1^{122}$ described a case in which a resected endometriotic cyst was lined by stratified, severely

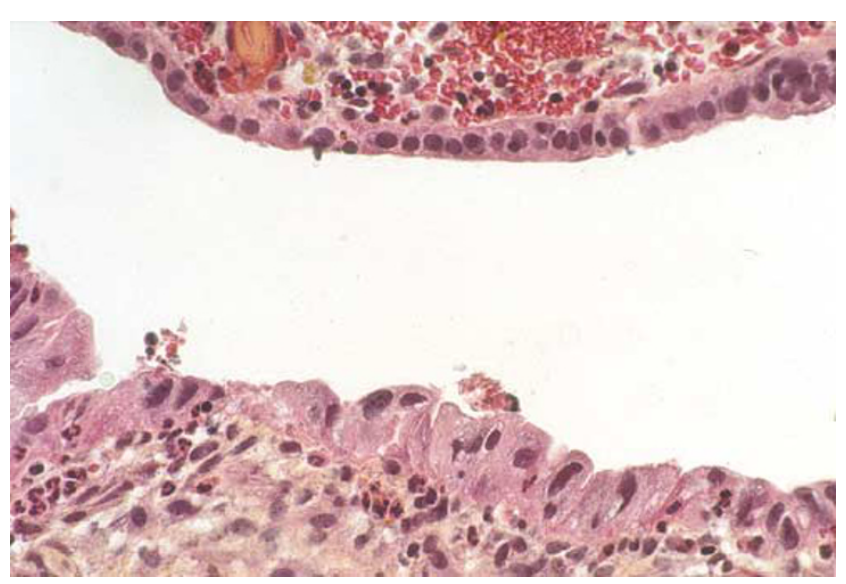

Figure 7 Endometriotic cyst lined by atypical cells with eosinophilic cytoplasm. 
atypical hobnail cells; 3 years later, the patient had a clear cell carcinoma in the residual ovarian tissue; these authors suggested that such lining changes are preneoplastic. A single study of ploidy of atypical cyst lining cells has been performed. The investigators noted that all of the cases with 'mild' atypia and no stratification were diploid, but that three of six cases with 'severe' atypia, stratification and tufting, were aneuploid, suggesting a neoplastic potential. ${ }^{120}$

\section{Molecular Genetic Data}

\section{Endometriosis}

A small number of studies have analyzed genetic alterations in endometriosis unassociated with carcinomas. ${ }^{124-131}$ They have shown that most benign-appearing ovarian endometriotic cysts are monoclonal. ${ }^{124,125,129,130,131}$ Jiang et $a l^{124,132}$ have shown loss of heterozygosity at several loci on chromosomes 9q, 11q and 22q in less than $20 \%$ of ovarian endometriotic cysts and Sato et $a 1^{126}$ found a higher frequency of $\mathrm{LOH}$ of $56 \%$ at $10 \mathrm{q} 23.3$. PTEN mutations have been noted in $21 \%$ of endometriotic cysts. ${ }^{126}$ Several studies have failed to demonstrate either mutations or overexpression of $p 53^{127,128,133}$ or KRAS mutations ${ }^{128}$ in benign endometriotic cysts.

\section{Endometrioid carcinoma}

Low-grade ovarian endometrioid adenocarcinomas have been shown to have different genetic alterations than other histologic subtypes. ${ }^{126-143}$ Mutations of CTNNB1, the gene that encodes $\beta$-catenin have been reported in $16-54 \%$ of cases. ${ }^{134-140}$ Tumors associated with such mutations are more frequently low-grade and stage and have a favorable prognosis. ${ }^{134,135,139}$ PTEN, which is frequently mutated in endometrioid carcinomas of the endometrium is mutated in approximately $20 \%$ of ovarian endometrioid carcinomas. ${ }^{126,128}$ TP53 mutations or overexpression or both have been reported in $42-63 \%$ of ovarian endometrioid adenocarcinomas. ${ }^{127,128}$ Microsatellite instability has been reported in $12-19 \%$ of ovarian endometrioid adenocarcinomas. ${ }^{140,141}$

A small number of studies have examined ovarian endometrioid adenocarcinomas and adjacent synchronous endometriosis for common genetic events. Jiang et $a l^{132}$ have demonstrated that endometriosis and adjacent endometrioid carcinoma share common genetic events such as loss of heterozygosity at the same loci involving the same allele, and have the same pattern of $\mathrm{X}$ chromosome inactivation (albeit in only two of two cases examined). Similarly, several groups of investigators have documented identical PTEN mutations and $\mathrm{LOH}$ patterns at 10 q23 in endometriotic cysts or endometriosis coexisting with endometrioid carcinomas. ${ }^{126,142}$ These findings are consistent with the morphologic observations of endometrioid carcinoma arising in endometriosis with mutations of PTEN and CTNNB1.

In contrast, high-grade or poorly differentiated endometrioid carcinomas have demonstrated similar genetic alterations to high-grade serous carcinoma. $^{49}$

\section{Clear cell carcinomas}

Because of their rarity, much less data are available regarding the genetic alterations in clear cell adenocarcinomas. Recent molecular genetic studies have shown significantly lower TP53 mutation rates and $\mathrm{LOH}$ rates at $17 \mathrm{p} 13^{143}$ in clear cell carcinomas than in other types of ovarian carcinomas and several studies have demonstrated that gene expression profiles may distinguish clear cell carcinoma from other histologic subtypes. ${ }^{144,145}$ One study has shown identical LOH patterns at 10q23 and PTEN mutations in endometriotic cysts adjacent to clear cell carcinomas. ${ }^{126}$ These findings suggest that some clear cell tumors arise from ovarian and pelvic endometriosis.

\section{Conclusions}

At least a subset of low-grade endometrioid adenocarcinomas arise from ovarian endometriosis with mutations of CTNNB1 ( $\beta$-catenin) and PTEN, probably progressing through endometrial-like hyperplasia as an intermediate step. High-grade endometrioid carcinomas probably arise via a different pathway involving TP53 mutations.

\section{Summary}

The morphologic and molecular genetic data support different pathways of development for each of the major histologic types of ovarian carcinoma:

1. Low- and high-grade serous carcinoma most probably arise via different pathways, the former progressing along an adenoma-borderline tumorcarcinoma sequence involving mutations in $K R A S$ and $B R A F$ and the latter from alterations in surface epithelial inclusion glands involving mutations of TP53 and dysfunction of BRCA1 and/or BRCA2.

2. Mucinous carcinomas most probably arise via an adenoma-borderline tumor-carcinoma sequence with mutations of KRAS.

3. Endometrioid carcinomas arise from endometriosis with mutations of CTNNB1 (the gene encoding $\beta$-catenin) and PTEN.

4. The genetic alterations in clear cell carcinoma are the least investigated but also support an origin from endometriosis.

The data also suggest that most lowgrade, relatively indolent ovarian carcinomas of serous, mucinous and endometrioid type arise from pre-existing 
cystadenomas or endometriosis, whereas most highgrade serous carcinomas arise without an easily identifiable precursor lesion.

\section{References}

1 Scully RE, Young RH, Clement PB. Tumors of the ovary, maldeveloped gonads, fallopian tube, and broad ligament. In: Atlas of Tumor Pathology, 3rd series; fascicle 23. Armed Forces Institute of Pathology: Washington, DC, 1998.

2 Lee KR, Tavassoli FA, Prat J, et al. Surface epithelial stromal tumors. In: Tavassoli FA, Devilee P (eds). Pathology and Genetics: Tumours of the Breast and Genital Organs. IARC Press: Lyon, France, 2003, pp 117-145.

3 Gillett WR. Artefactual loss of human ovarian surface epithelium: potential clinical significance. Reprod Fertil Dev 1991;3:93-98.

4 Sherman ME, Lee JS, Burks TR, et al. Histopathologic features of ovaries at increased risk for carcinoma. A case controlled analysis. Int J Gynecol Pathol 1999; 18:151-157.

5 Gusberg SB, Deligdisch L. Ovarian dysplasia. A study of identical twins. Cancer 1984;54:1-4.

6 Bell DA, Scully RE. Early de novo ovarian carcinoma. A study of fourteen cases. Cancer 1994;73: 1859-1864.

7 Graham JB, Graham RM. Cul-de-sac puncture in the diagnosis of early ovarian carcinoma. J Obstet Gynaecol Br Commonw 1967;74:371-378.

8 Graham JB, Graham RM, Schueller EF. Preclinical detection of ovarian cancer. Cancer 1964;17:14141432.

9 Graham RM, Schueller EF, Graham JB. Detection of ovarian cancer at an early stage. Obstet Gynecol 1965;26:151-156.

10 Hutson R, Ramsdale J, Wells M. p53 protein expression in putative precursor lesions of epithelial ovarian cancer. Histopathology 1995;27:367-371.

11 Werness BA, Parvatiyar P, Ramus SJ, et al. Ovarian carcinoma in situ with germline BRCA1 mutation and loss of heterozygosity at BRCA1 and TP53. J Natl Cancer Inst 2000;92:1088-1091.

12 Gil J, Deligdisch L. Interactive morphometric procedures and statistical analysis in the diagnosis of ovarian dysplasia and carcinoma. Pathol Res Pract 1989;185:680-685.

13 Tsukahara Y, Shiozawa I, Sakai Y, et al. Study on the histogenesis of ovarian tumors with special reference to five clinical cases with common epithelial tumors detected during the preclinical stage. Acta Obst Gynaec Jpn 1982;34:959-965.

14 Plaxe SC, Deligdisch L, Dottino PR, et al. Ovarian intraepithelial neoplasia demonstrated in patients with Stage I ovarian carcinoma. Gynecol Oncol 1990;38:367-372.

15 Werness BA, Afify AM, Bielat KL, et al. Altered surface and cyst epithelium of ovaries removed prophylactically from women with a family history of ovarian cancer. Hum Pathol 1999;30:151-157.

16 Salazar H, Godwin AK, Daly MB, et al. Microscopic benign and invasive malignant neoplasms and a cancer-prone phenotype in prophylactic oophorectomies. J Natl Cancer Inst 1996;88:1810-1820.
17 Stratton JF, Buckley CH, Lowe D, et al. Comparison of prophylactic oophorectomy specimens from carriers and noncarriers of a BRCA1 or BRCA2 gene mutation. J Natl Cancer Inst 1999;91:626-628.

18 Barakat RR, Federici MG, Saigo PE, et al. Absence of premalignant histologic, molecular, or cell biologic alterations in prophylactic oophorectomy specimens from BRCA1 heterozygotes. Cancer 2000;89:383-390.

19 Tresserra F, Grases PJ, Labastida R, et al. Histological features of the contralateral ovary in patients with unilateral ovarian cancer: a case control study. Gynecol Oncol 1998;71:437-441.

20 Westhoff C, Murphy P, Heller D, et al. Is ovarian cancer associated with an increased frequency of germinal inclusion cysts? Am J Epidemiol 1993;138: 90-93.

21 Resta L, Russo S, Colucci GA, et al. Morphologic precursors of ovarian epithelial tumors. Obstet Gynecol 1993;82:181-186.

22 Deligdisch L, Gil J, Kerner H, et al. Ovarian dysplasia in prophylactic oophorectomy specimens: cytogenetic and morphometric correlations. Cancer 1999;86: 1544-1550.

23 Fraumeni JFJ, Grundy GW, Creagan ET, et al. Six families prone to ovarian cancer. Cancer 1975;36: 364-369.

24 Piek JMJ, Verheijen RHM, Menko FH. Expression of differentiation and proliferation related proteins in epithelium of prophylactically removed ovaries from women with a hereditary female adnexal cancer predisposition. Histopathology 2003;43:26-32.

25 Mittal KR, Zeleniuch-Jacquotte A, Cooper JL. Contralateral ovary in unilateral ovarian carcinoma: a search for preneoplastic lesions. Int J Gynecol Pathol 1993;12:59-63.

26 Scully RE. Minimal cancer of the ovary. Clin Oncol 1982;1:379-387.

27 Chen KT, Schooley JL, Flam MM. Peritoneal carcinomatosis after prophylactic oophorectomy in familial ovarian cancer syndrome. Obstet Gynecol 1985;66: 93S-95S.

$28 \mathrm{Lu} \mathrm{KH}$, Garber JE, Cramer DW, et al. Occult ovarian tumors in women with BRCA1 or BRCA2 mutations undergoing prophylactic oophorectomy. J Clin Oncol 2000;18:2728-2732.

29 Colgan TJ, Murphy J, Cole DE, et al. Occult carcinoma in prophylactic oophorectomy specimens: prevalence and association with BRCA germline mutation status. Am J Surg Pathol 2001;25:1283-1289.

30 Colgan TJ. Challenges in the early diagnosis and staging of fallopian-tube carcinomas associated with BRCA mutations. Int J Gynecol Pathol 2003;22: 109-120.

31 Agoff SN, Mendelin JE, Grieco VS, et al. Unexpected gynecologic neoplasms in patients with proven or suspected BRCA-1 or -2 mutations: implications for gross examination, cytology, and clinical follow-up. Am J Surg Pathol 2002;26:171-178.

32 Paley PJ, Swisher EM, Garcia RL. Occult cancer of the fallopian tube in BRCA-1 germline mutation carriers at prophylactic oophorectomy: a case for recommending hysterectomy at surgical prophylaxis. Gynecol Oncol 2001;83:445-447.

33 Piek JM, Van Diest PJ, Kweemer RP, et al. Dysplastic changes in prophylactically removed fallopian tubes of women predisposed to developing ovarian cancer. J Pathol 2001;195:451-456. 
34 Carcangiu ML, Radice P, Manoukian S, et al. Atypical epithelial proliferation in fallopian tubes in prophylactic salpingo-oophorectomy specimens from BRCA1 and BRCA2 germline mutation carriers. Int J Gynecol Pathol 2003;23:35-40.

35 Piek JMJ, Dorsman JC, Zweemer RP, et al. Women harboring BRCA1/2 germline mutations are at risk for breast and female adnexal carcinoma. Int J Gynecol Pathol 2003;22:315-316.

36 Balkwill F, Bast RC, Berek J, et al. Current research and treatment for epithelial ovarian cancer a position paper from the Helene Harris Memorial Trust. Eur J Cancer 2003;39:1818-1827.

37 Pothuri B, Leitao M, Barakat R, et al. Genetic analysis of ovarian carcinoma histogenesis. Gynecol Oncol 2001;80:277.

38 Nnene IO, Nieto JJ, Crow JC, et al. Cell cycle and apoptotic proteins in relation to ovarian epithelial morphology. Gynecol Oncol 2004;92:247-251.

39 Kupryjanczyk J, Bell DA, Yandell DW, et al. P53 expression in ovarian borderline tumors and stage I carcinomas. Am J Clin Pathol 1994;102:671-676.

40 Teneriello MG, Ebinba M, Linnoila RI, et al. p53 and Ki-ras gene mutations in epithelial ovarian neoplasms. Cancer Res 1993;53:3103-3108.

41 Wertheim I, Muto MG, Welch WR, et al. P53 gene mutation in human borderline epithelial ovarian tumors. J Natl Cancer Inst 1994;86:1549-1551.

42 Jacobs I, Lancaster J. The molecular genetics of sporadic and familial epithelial ovarian cancer. Int J Gynecol Cancer 1996;6:337-355.

43 Singer G, Oldt III R, Cohen Y, et al. Mutations in BRAF and KRAS characterize the development of low-grade ovarian serous carcinoma. J Nat Cancer Inst 2003;95:484-486.

44 Kohler MF, Kerns BM, Humphrey PA, et al. Mutation and over expression of p53 in early-stage epithelial ovarian cancer. Obstet Gynecol 1993;81: 643-650.

45 Chan WY, Cheung KK, Schorge JO, et al. Bc1-2 and p53 protein expression, apoptosis, and p53 mutation in human epithelial ovarian cancers. Am J Pathol 2000;156:409-417.

46 Haas CJ, Diebold J, Hirschmann A, et al. In serous ovarian neoplasms the frequency of Ki-ras mutations correlates with their malignant potential. Virchows Arch 1999;434:117-120.

47 Caduff R, Svoboda-Newman S, Ferguson A, et al. Comparison of mutations of Ki-Ras and p53 immunoreactivity in borderline and malignant epithelial ovarian tumors. Am J Surg Pathol 2001;23:323-328.

48 Geisler JP, Hatterman-Zogg MA, Rathe JA, et al. Frequency of BRCA1 dysfunction in ovarian cancer. J Natl Cancer Inst 2002;94:61-67.

49 Hilton JL, Geisler JP, Rathe JA, et al. Inactivation of BRCA1 and BRCA2 in ovarian cancer. J Natl Cancer Inst 2002;94:1396-1406.

50 Shridhar V, Lee J, Pandita A, et al. Genetic analysis of early-versus late-stage ovarian tumors. Cancer Res 2001;61:5895-5904.

51 Bell DA, Scully RE. Ovary In: Henson DE, AlboresSaavedra J (eds). Pathology of Incipient Neoplasia, 3rd edn. Oxford University Press: New York, NY, 2001, pp 419-440.

52 Bourne TH, Whitehead MJ, Campbell S, et al. Ultrasound screening for familial ovarian cancer. Gynecol Oncol 1991;43:92-97.
53 Horiuchi A, Itoh K, Shimizu M, et al. Toward understanding the natural history of ovarian carcinoma development: a clinicopathological approach. Gynecol Oncol 2003;88:309-317.

54 Scully RE, Bell DA, Abu-Jawdeh GM. Update on early ovarian cancer and cancer developing in benign ovarian tumors In: Sharp F, Mason P, Blackett T, Berek J (eds). Ovarian Cancer 3. Chapman \& Hall Medical: New York, 1995, pp 139-144.

55 Puls LE, Powell DE, DePriest PD, et al. Transition from benign to malignant epithelium in mucinous and serous ovarian cystadenocarcinoma. Gynecol Oncol 1992;47:53-57.

56 Penson RT, Sahani D, Bell DA. A 52-year-old woman with postmenopausal bleeding and a cystic ovarian mass. N Engl J Med, in press.

57 Smith Sehdev AE, Sehdev PS, Kurman RJ. Noninvasive and invasive micropapillary (low-grade) serous carcinoma of the ovary: a clinicopathologic analysis of 135 cases. Am J Surg Pathol 2003;27:725-736.

58 Eichhorn JH, Bell DA, Young RH, et al. Ovarian serous borderline tumors with micropapillary and cribriform patters: a study of 40 cases and comparison with 44 cases without these patterns. Am J Surg Pathol 1999;23:397-409.

59 Slomovitz BM, Caputo TA, Gretz III HF, et al. A comparative analysis of 57 serous borderline tumors with and without a noninvasive micropapillary component. Am J Surg Pathol 2002;26:592-600.

60 Burks RT, Sherman ME, Kurman RJ. Micropapillary serous carcinoma of the ovary. A distinctive lowgrade carcinoma related to serous borderline tumors. Am J Surg Pathol 1996;20:1319-1330.

61 Seidman JD, Kurman RJ. Subclassification of serous borderline tumors of the ovary into benign and malignant types. A clinicopathologic study of 65 advanced stage cases. Am J Surg Pathol 1996;20: 1331-1345.

62 Marks JR, Davidoff AM, Kerns BJ, et al. Overexpression and mutation of p53 in epithelial ovarian cancer. Overexpression and mutation of p53 in epithelial ovarian cancer. Cancer Res 1991;51:2979-2984.

$63 \mathrm{Kmet}$ LM, Cook LS, Magliocco AM. A review of p53 expression and mutation in human benign, low malignant potential, and invasive epithelial ovarian tumors. Cancer 2003;97:389-404.

64 Berchuck A, Kohler MF, Hopkins MP, et al. Overexpression of p53 is not a feature of benign and earlystage borderline epithelial ovarian tumors. Gynecol Oncol 1994;52:232-236.

65 Imai S, Kiyozuka Y, Nishimura H, et al. Overexpression of the tumor suppressor gene p53 in human ovarian tumor tissues and its correlation with clinical stage. Int J Oncol 1994;4:1097-1103.

66 Thomas NA, Neville PJ, Baxter SW, et al. Genetic analysis of benign ovarian tumors. Int $\mathrm{J}$ Cancer 1996;105:499-505.

67 Zheng J, Benedict WF, Xu H-J, et al. Genetic disparity between morphologically benign cysts contiguous to ovarian carcinomas and solitary cystadenomas. J Natl Cancer Inst 1996;87:1146-1153.

68 Wolf NG, Abdul-Karin FW, Schork NJ, et al. Origins of heterogeneous ovarian carcinomas. A molecular cytogenetic analysis of histologically benign, low malignant potential malignant potential, and fully malignant components. Am J Pathol 1996;149: 511-520. 
69 Tapper J, Kettunen E, El-Rifai W, et al. Changes in gene expression during progression of ovarian carcinoma. Cancer Gene Cytogenet 2001;128:1-6.

70 Matias-Guiu X, Prat J. Molecular pathology of ovarian carcinomas. Virchows Arch 1996;433:103-111.

71 McCluskey LL, Dubeau L. Biology of ovarian cancer. Curr Opin Oncol 1997;9:465-470.

72 Auersperg N, Edelson MI, Mok SC, et al. The biology of ovarian cancer. Semin Oncol 1998;25:281-304.

73 Singer G, Kurman RJ, Chang HW, et al. Diverse tumorigenic pathways in ovarian serous carcinoma. Am J Pathol 2002;160:1223-1228.

74 Shih IM, Kurman RJ. Ovarian tumorigenesis: a proposed model based on morphological and molecular genetic analysis. Am J Pathol 2004;164:1511-1518.

75 Cuatrecasas M, Villanueva A, Matias-Guiu X, et al. K-ras mutations in mucinous ovarian tumors: a clinicopathologic and molecular study of 95 cases. Cancer 1997;79:1581-1586.

76 Singer G, Oldt III R, Cohen Y, et al. Mutations in BRAF and KRAS characterize the development of low-grade ovarian serous carcinoma. JNCI 2003;95: 484-486.

77 Russell SE, McCluggage. A multistep model for ovarian tumorigenesis: the value of mutation analysis in the KRAS and BRAF genes. J Pathol 2004;203: 617-619.

78 Sieben NLG, Macropoulos P, Roemen GMJM, et al. In ovarian neoplasms, BRAF, but not KRAS, mutations are restricted to low-grade serous tumours. J Pathol 2004;202:336-340.

79 Iwabuchi H, Sakamoto M, Sakunaga H, et al. Genetic analysis of benign, low-grade, and high-grade ovarian tumors. Cancer Res 1995;55:6172-6180.

80 Sonoda G, Palazzo J, Du Manoir S, et al. Comparative genomic hybridization detects frequent overrepresentation of chromosomal material from 3q26, 8q24, and $20 q 13$ in human ovarian carcinomas. Genes Chromosomes Cancer 1997;20:320-328.

81 Arnold N, Hagele L, Walz L, et al. Overrepresentation of $3 q$ and $8 q$ material and loss of $18 q$ material are recurrent findings in advanced human ovarian cancer. Genes Chromosomes Cancer 1996;16:46-54.

82 Kiechle M, Jacobsen A, Schwarz-Boeger U, et al. Comparative genomic hybridization detects genetic imbalances in primary ovarian carcinomas as correlated with grade of differentiation. Cancer 2001;91: 534-540.

83 Lee KR, Scully RE. Mucinous tumors of the ovary: a clinicopathologic study of 196 borderline tumors (of intestinal type) and carcinomas, including an evaluation of 11 cases with 'pseudomyxoma peritonei'. Am J Surg Pathol 2000;24:1447-1464.

84 Riopel MA, Ronnett BM, Kurman RJ. Evaluation of diagnostic criteria and behavior of ovarian intestinal-type mucinous tumors: atypical proliferative (borderline) tumors and intraepithelial, microinvasive, invasive, and metastatic carcinomas. Am J Surg Pathol 1999;23:617-635.

85 Lee KR, Nucci MR. Ovarian mucinous and mixed epithelial carcinomas of Mullerian (endocervicallike) type: a clinicopathologic analysis of four cases of an uncommon variant associated with endometriosis. Int J Gynecol Pathol 2003;22:42-51.

86 Shappell HW, Riopel MA, Smith Sehdev AE, et al. Diagnostic criteria and behavior of ovarian seromucinous (endocervical-type mucinous and mixed celltype) tumors. Am J Surg Pathol 2002;26:1529-1541.
87 Mandai M, Konishi I, Kuroda H, et al. Heterogeneous distribution of K-ras-mutated epithelia in mucinous ovarian tumors with special reference to histopathology. Hum Pathol 2001;29:34-40.

88 Garrett AP, Lee KR, Colitti CR, et al. K-ras mutation may be an early event in mucinous ovarian tumor igenesis. Int J Gynecol Pathol 2001;20:244-251.

89 Gemignani ML, Schlaerth AC, Bogomolniy F, et al. Role of KRAS and BRAF gene mutations in mucinous ovarian carcinoma. Gynecol Oncol 2003;90:378-381.

90 Brinton LA, Gridley G, Persson I, et al. Cancer risk after a hospital discharge diagnosis of endometriosis. Am J Obstet Gynecol 1997;176:572-579.

91 Borgfeldt C, Andolf E. Cancer risk after hospital discharge diagnosis of benign ovarian cysts and endometriosis. Acta Obstet Gynecol Scand 2004;83: 395-400.

92 Erzen M, Rakar S, Klancnik B, et al. Endometriosisassociated ovarian carcinoma (EAOC): an entity distinct from other ovarian carcinomas as suggested by a nested case-control study. Gynecol Oncol 2001; 83:100-108.

93 Modesitt SC, Tortolero-Luna G, Robinson JB, et al. Ovarian and extraovarian endometriosis-associated cancer. Obstet Gynecol 2002;100:788-795.

94 Stern RC, Dash R, Bentley RC, et al. Malignancy in endometriosis: frequency and comparison of ovarian and extraovarian types. Int J Gynecol Pathol 2001; 20:133-139.

95 Mostoufizadeh M, Scully RE. Malignant tumors arising in endometriosis. Clin Obstet Gynecol 1980; 23:951-963.

96 Scully RE, Richardson GS, Barlow JF. The development of malignancy in endometriosis. Clin Obstet Gynecol 1966;9:384-411.

97 Clement PB, Scully RE. Extrauterine mesodermal (müllerian) adenosarcoma. A clinicopathologic analysis of five cases. Am J Clin Pathol 1987;69:276-283.

98 Clement PB. Pathology of endometriosis. Path Annual 1990;25:245-295.

99 Aure JC, Hoeg K, Kolstad P. Carcinoma of the ovary and endometriosis. Acta Obstet Gynecol Scand 1971; 50:63-67.

100 Curling OM, Hudson CN. Endometrioid tumours of the ovary. Br J Obstet Gynaecol 1975;82:405-411.

101 Czernobilsky B, Silverman BB, Mikuta JJ. Endometrioid carcinoma of the ovary. Cancer 1970;26: 1141-1152.

102 Fathalla MF. Malignant transformation in ovarian endometriosis. J Obstet Gynaecol $\mathrm{Br}$ Common 1967;74:85-92.

103 Kurman RJ, Craig JM. Endometrioid and clear cell carcinoma of the ovary. Cancer 1972;29:1653-1664.

104 Russell P. The pathological assessment of ovarian neoplasms. I. Introduction to the common 'epithelial' tumours and analysis of benign 'epithelial' tumors. Pathology 1979;11:5-26.

105 McMeekin DS, Burger RA, Manetta A, et al. Endometrioid adenocarcinoma of the ovary and its relationship to endometriosis. Gynecol Oncol 1995;59:81-86.

106 De Preist PD, Banks ER, Powell DE, et al. Endometrioid carcinoma of the ovary and endometriosis: the association in postmenopausal women. Gynecol Oncol 1992;47:71-75.

107 Heaps JM, Nieberg RK, Berek JS. Malignant neoplasms arising in endometriosis. Obstet Gynecol 1990;75:1023-1028. 
108 Roth LM, Emerson RE, Ulbright TM. Ovarian endometrioid tumors of low malignant potential: a clinicopathologic study of 30 cases with comparison to well-differentiated endometrioid adenocarcinoma. Am J Surg Pathol 2003;27:1253-1259.

109 Rutgers JL, Scully RE. Müllerian mucinous papillary cystadenomas of borderline malignancy: a clinicopathological analysis of 30 cases. Cancer 1988;61: 340-348.

110 Rutgers JL, Scully RE. Ovarian mixed epithelial papillary cystadenoma of borderline malignancy of müllerian type: a clinicopathological analysis of 36 cases. Cancer 1988;61:546-554.

111 Czernobilsky B, Morris WJ. A histologic study of ovarian endometriosis with emphasis on hyperplastic and atypical changes. Obstet Gynecol 1988;53: 318-323.

112 LaGrenade A, Silverberg SG. Ovarian tumors associated with atypical endometriosis. Hum Pathol 1988; 19:1080-1084.

113 Seidman JD. Prognostic importance of hyperplasia and atypia in endometriosis. Int J Gynecol Pathol 1996;15:1-9.

114 Sainz la Cuesta R, Eichhorn JH, Rice LW, et al. Histologic transformation of benign endometriosis to early epithelial ovarian cancer. Gynecol Oncol 1988;60:238-244.

115 Fukunaga M, Nomura K, Ishikawa E, et al. Ovarian atypical endometriosis: its close association with malignant epithelial tumours. Histopathology 1997; 30:249-255.

116 Prefumo F, Todeschini F, Fulcheri E, et al. Epithelial abnormalities in cystic ovarian endometriosis. Gynecol Oncol 2002;84:280-284.

117 Cramer DW, Hutchison GB, Welch WR, et al. Determinants of ovarian cancer risk. I. Reproductive experiences and family history. J Natl Cancer Inst 1988;71:711-716.

118 Weiss NS, Lyon JL, Krishnamurthy S. Non-contraceptive estrogen use and the occurrence of ovarian cancer. J Natl Cancer Inst 1982;68:95-98.

119 Kurman RJ, Norris HJ. Evalution of criteria for distinguishing atypical endometrial hyperplasia from well-differentiated carcinoma. Cancer 1982; 49:2547-2559.

120 Ballouk F, Ross JS, Wolf BC. Ovarian endometriotic cysts. An analysis of cytologic atypia and DNA ploidy patterns. Am J Clin Pathol 1990;102:415-519.

121 Fukunaga M, Ushigome S. Epithelial metaplastic changes in ovarian endometriosis. Mod Pathol 1998; 11:784-788.

122 Moll UM, Chumas JC, Chalas E, et al. Ovarian carcinoma arising in atypical endometriosis. Obstet Gynecol 1990;75:537-539.

123 Chalas E, Chumas J, Barbieri R, et al. Nuclear organizer regions in endometriosis, atypical endometriosis, and clear cell and endometrioid carcinomas. Gynecol Oncol 1991;40:260-263.

124 Jiang X, Hitchcock A, Bryan EJ, et al. Microsatellite analysis of endometriosis reveals loss of heterozygosity at candidate ovarian tumor suppressor gene loci. Cancer Res 1996;56:3534-3539.

125 Nilbert M, Pejovic T, Mandahl N, et al. Monoclonal origin of endometriotic cysts. Int J Gynecol Cancer 1995;5:61-63.

126 Sato N, Tsunoda H, Nishida M, et al. Loss of heterozygosity on 10q 23.3 and mutation of the tumor suppressor gene PTEN in benign endometrial cyst of the ovary: possible sequence progression from benign endometrial cyst to endometrioid carcinoma and clear cell carcinoma of the ovary. Cancer Res 2000; 60:7052-7056.

127 Nezhat F, Cohen C, Rahaman J, et al. Comparative immunohistochemical studies of bcl-2 and p53 proteins in benign and malignant ovarian endometriotic cysts. Cancer 2002;94:2935-2940.

128 Okuda T, Otsuka J, Sekizawa A, et al. p53 mutations and overexpression affect prognosis of ovarian endometrioid cancer but not clear cell cancer. Gynecol Oncol 2003;88:318-325.

129 Jimbo H, Hitomi Y, Yoshikawa $H$, et al. Evidence for monoclonal expansion of epithelial cells in ovarian endometrial cysts. Am J Pathol 1997;150:1173-1178.

130 Tamura M, Fukaya T, Murakami T, et al. Analysis of clonality in human endometriotic cysts based on evaluation of $\mathrm{X}$ chromosome inactivation in archival formalin-fixed, paraffin-embedded tissue. Lab Invest 1998;78:213-218.

131 Yano $\mathrm{T}$, Jimbo $\mathrm{H}$, Yoshikawa $\mathrm{H}$, et al. Molecular analysis of clonality in ovarian endometrial cysts. Gynecol Obstet Invest 1999;47(Suppl 1):41-45.

132 Jiang X, Morland SJ, Hitchcock A, et al. Allelotyping of endometriosis with adjacent ovarian carcinoma reveals evidence of a common lineage. Cancer Res 1990;58:1707-1712.

133 Vercellini P, Trecca D, Oldani S, et al. Analysis of p53 and ras gene mutations in endometriosis. Gynecol Obstet Invest 1994;38:70-71.

134 Palacios J, Gamallo C. Mutations in the beta-catenin gene (CTNNB1) in endometrioid ovarian carcinomas. Cancer Res 1990;58:1344-1347.

135 Gamallo C, Palacios J, Moreno G, et al. B-catenin expression pattern in stage I and II ovarian carcinomas. Relationship with B-catenin gene mutations, clinicopathological features and clinical outcome. Am J Pathol 1999;155:527-536.

$136 \mathrm{Wu}$ R, Zhai Y, Fearon ER, et al. Diverse mechanisms of B-catenin deregulation in ovarian endometrioid adenocarcinomas. Cancer Res 2001;61:8247-8255.

137 Wright K, Wilson P, Morland S, et al. Beta-catenin mutation and expression analysis in ovarian cancer: exon 3 mutations and nuclear translocation in $16 \%$ of endometrioid tumours. Int J Cancer 1999;82:625-629.

138 Sagae S, Kobayashi K, Nishioka Y, et al. Mutational analysis of beta-catenin gene in Japanese ovarian carcinomas: frequent mutations in endometrioid carcinomas. Jpn J Cancer Res 1999;90:510-515.

139 Saegusa M, Okayasu I. Frequent nuclear beta-catenin accumulation and associated mutations in endometrioid-type endometrial and ovarian carcinomas with squamous differentiation. J Pathol 2001;194:59-67.

140 Moreno-Bueno G, Gamallo C, Perez-Gallego L, et al. Beta-catenin expression pattern, beta-catenin gene mutations, and microsatellite instability in endometrioid ovarian carcinomas and synchronous endometrial carcinomas. Diagn Mol Pathol 1990;10: 116-122.

141 Gras E, Catasus L, Arguelles R, et al. Microsatellite instability, MLH-1 promoter hypermethylation, and frameshift mutations at coding mononucleotide repeat microsatellites in ovarian tumors. Cancer 2001; 92:2829-2836

142 Obata K, Morland SJ, Watson RH, et al. Frequent PTEN/MMAC mutations in endometrioid but not 
serous or mucinous epithelial ovarian tumors. Cancer Res 1998;58:2095-2097.

143 Okada S, Tsuda H, Takarabe T, et al. Allelotype analysis of common epithelial ovarian cancers with special reference to comparison between clear cell adenocarcinoma with other histological types. J Cancer Res 1990;93:798-806.

144 Schwartz DR, Kardia SLR, Shedden KA, et al. Gene expression in ovarian cancer reflects both morpho- logy and biological behavior, distinguishing clear cell from other poor-prognosis ovarian carcinomas. Cancer Res 2002;62:4722-4729.

145 Tsuchiya A, Sakamoto M, Yasuda J, et al. Expression profiling in ovarian clear cell carcinoma. Identification of hepatocyte nuclear factor- $1 \beta$ as a molecular marker and a possible molecular target for therapy of ovarian clear cell carcinoma. Am J Pathol 2003;163: 2503-2512. 